Article

\title{
An Integrated Decision Framework for Material Selection Procedure: A Case Study in a Detergent Manufacturer
}

\author{
Mehtap Dursun * and Özlem Arslan \\ Industrial Engineering Department, Galatasaray University, Faculty of Engineering and Technology, Ortakoy, \\ Istanbul 34349, Turkey; ozlemarslan@gmail.com \\ * Correspondence: mdursun@gsu.edu.tr; Tel.: +90-2122274480 (ext. 437)
}

Received: 27 October 2018; Accepted: 15 November 2018; Published: 20 November 2018

check for updates

\begin{abstract}
The new product development process (NPD) is considered to be the key factor of competition among different markets. The identification of a suitable material is an important issue in the conception and improvement of new products. Material selection is seen as an important multi-criteria decision making $(\mathrm{MCDM})$ problem in engineering because of the requirement of considering multiple criteria from different dimensions. Improper material selection may negatively affect the success of a firm. The purpose of this study is to specify the importance of selection attributes, which are considered to evaluate washing liquid that meets the needs of both customers and firms. Then, it objects to choose the most appropriate alternative among various formulations. A fuzzy MCDM methodology based on quality function deployment (QFD), 2-tuple fuzzy linguistic representation, and linguistic hierarchies is presented. QFD is used to incorporate customer requirements into the evaluation process. The 2-tuple fuzzy modeling and linguistic hierarchies are employed to combine multi-granular data given by experts. Finally, the fuzzy COPRAS (Complex Proportional Assessment) method is used to choose the most suitable alternative. The implementation of the developed method is presented by a case study conducted on a detergent manufacturer located in Turkey.
\end{abstract}

Keywords: COPRAS (Complex Proportional Assessment); linguistic hierarchies; material selection; new product development; quality function deployment; 2-tuple fuzzy linguistic representation

\section{Introduction}

New product development (NPD) is considered as a major competitive advantage source for organizations, and understanding the aspects that contribute to new product success is an important managerial issue [1]. It is based on converting an idea into a visible, touchable entity. Obtaining a new product can be provided by taking the most appropriate decisions at each level of the development process; therefore, every step taken by decision makers is very important. In addition, the effective management of the product development process is also critical.

NPD has various phases, including idea production, product concept selection, prototype improvement and testing, product launch, and commercialization, which have significant contributions to new product success [2]. The purpose is meeting the desires of higher quality and performance at lower cost. The development process starts with producing new ideas and converting these ideas into a proposal. Inapplicable ideas are eliminated, while applicable ideas are elaborated. After that, a survey should be conducted among target consumers in order to determine the necessities of consumers and compare these necessities according to a company's policy. Cost-benefit analysis is done by taking 
designated criteria into account. If all of these evaluations are positive, the new product development process starts.

In the new product development process, materials selection has a critical role in manufacturing as well as in the conception process, and it has a major role in assuring the requested performance of the products for different engineering problems [3]. The types of materials are key factors that are responsible for interactions between customers and users, and they play a fundamental role in the whole product design and manufacturing procedure. The material selection procedure is also critical to achieve the needs of cost diminution and performance elevation. In today's competitive environment, the identification of the most suitable material for a specific output is important for the survival of enterprises. In the most recent applications, engineers and designers choose the appropriate material to satisfy the necessities of the product, such as high performance, weight savings, and cost minimization [4].

Material selection is seen as a multi-criteria decision making (MCDM) problem that needs to consider multiple conflicting criteria. Being able to select proper materials and succeed in matching the requirements to the production process is significant. Improper material selection may affect the performance of products negatively; thus, the efficiency, success, and prestige of the firm are also poorly affected [5]. The goal of the material selection procedure is to constitute an effective product that gives maximum performance at minimum cost.

Only a few studies that have employed various MCDM methods for material selection can be found in the literature. Ballestero [6] proposed a decision-making methodology to select fabric for a textile company. Chatterjee and Chakraborty [7] employed MCDM models based on different preference rankings to resolve a material selection procedure. Girubba and Vinodh [8] utilized the VIKOR (VlseKriterijuska Optimizacija I Komoromisno Resenje) method as a MCDM aid to identify the most appropriate material for the instrument panel that was used in electric panels. Rahman et al. [9] proposed a decision scheme to make an ideal material selection for roof design. The procedure utilized the TOPSIS (Technique for Order Preference by Similarity to Ideal Solution) method to facilitate the selection process. Liu et al. [5] proposed an interval 2-tuple linguistic MCDM procedure to deal with the material selection in two different cases, for an automotive company and for a flywheel, respectively. Anojkumar et al. [10] introduced four different MCDM methods to select material for the pipes in the sugar industry by taking into account different alternatives and evaluation criteria. Liu et al. [11] integrated a DEMATEL (decision-making trial and evaluation laboratory)-based ANP (analytic network process) and VIKOR to resolve the bush material selection problem that consists of many interdependent attributes. Liao [12] presented an interval type 2 fuzzy MCDM for material evaluation. The method is illustrated in an engineering application of material selection in a jet fuel system. Govindan et al. [13] constructed a model to select the most appropriate construction material by utilizing the DEMATEL, ANP, and TOPSIS methods. Zandani et al. [14] used TODIM (TOmada de Decisao Interativa Multicriterio) for determining the most suitable materials. Zhang et al. [15] proposed an MCDM approach that integrates DEMATEL, GRA (grey relational analysis), ANP, and TOPSIS to determine the optimal green material. Recently, Mousavi-Nasab and Sotoudeh-Anvari [16] suggested a new MCDM methodology for a sustainable material evaluation process. Ercan and Bilal [17] employed an entropy-based simple additive weighting and AHP (Analytic Hierarchy Process) to determine the most appropriate material for a dental implant.

This paper objects to specify the importance of selection attributes, which are considered to evaluate a washing liquid that meets the needs of both customers and firms. Then, it objects to choose the most suitable alternative among diverse formulations. A fuzzy multi-criteria group decision-making approach (MCGDM), which is based on the principles of quality function deployment (QFD) 2-tuple fuzzy linguistic representation, and linguistic hierarchies, is presented. QFD is used to incorporate customer requirements into the evaluation process, while 2-tuple fuzzy linguistic representation and linguistic hierarchies are employed to unify multi-granular linguistic data provided 
by experts. Finally, the fuzzy COPRAS (Complex Proportional Assessment) method is used to select the most appropriate alternative.

\section{Materials and Methods}

\subsection{Quality Function Deployment}

Quality function deployment (QFD) is accepted as a significant product improvement tool, which objects to convert consumer expectations into activities to improve product and services [18]. QFD is a crucial approach that aims to respond to customer requirements (CRs) in developing a new product. To accomplish customer requirements while producing a product strictly depends on the capability of organizations. In these cases, QFD enables finding a common ground between customer requirements and the capability of organizations, and tries to get them closer to each other. Customer requirements are the basis of QFD methodology. This methodology is based on the idea of converting subjective customer needs into quantitative terms during the process of producing a product. When it is applied successfully, the cycle time can be reduced, and the production cost can be decreased. QFD is known and implemented by many firms around the world to enhance the quality of services and products for finding and satisfying consumer requirements. On the other hand, designating resources by considering customer needs leads to a reduction in cycle time and fall in production cost [19].

QFD has four matrices (product planning, part deployment, process planning, and production/operation planning matrices) that each conforms to a step of the product's improvement. Each matrix has its own task for phases in the product development process. The product planning matrix, which is also named the house of quality (HOQ), includes getting enough useful data from customers. Some specifications such as customer requirements and the capacity of organizations are recorded in this phase. It is an important phase due to its impact on the whole QFD process. Product concepts are decided, and parts that are able to meet customer requirements are selected in a part deployment matrix. In a process planning matrix, manufacturing processes are designated, and in a production/operation planning matrix, manufacturing operations are translated into production standards.

In this study, we use the HOQ matrix, which is the most frequently employed matrix in QFD. HOQ consists of seven cells, which each have a different task. Each cell clarifies a relationship among CRs (customer requirements) and TAs (technical attributes) and between the TAs.

\subsection{Fuzzy Set Theory}

Zadeh [20] introduced fuzzy set theory to cope with the subjectivity and imprecision involved in a problem. This theory is utilized to incorporate vague information into the decision process. A triangular fuzzy number $\widetilde{T}=(a, b, c)$ is represented as in Figure 1.

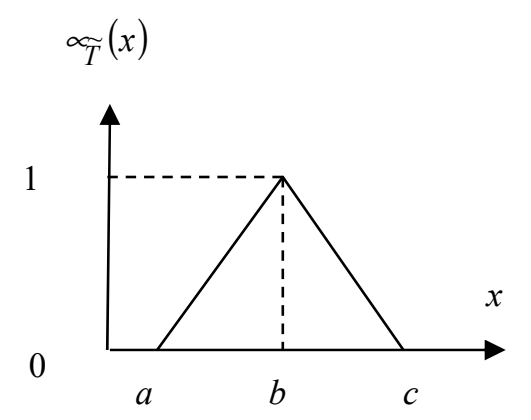

Figure 1. Illustration of a triangular fuzzy number. 
The membership function, $\mu_{\widetilde{T}}(x)$, of the fuzzy number $\widetilde{T}$ is delineated as:

$$
\mu_{\widetilde{T}}(x)= \begin{cases}0, & x \notin[a, c], \\ \frac{x-a}{b-a}, & x \in[a, b[ \\ 1, & x=b, \\ \frac{x-c}{b-c}, & x \in] b, c] .\end{cases}
$$

Let $\widetilde{T}_{1}=\left(a_{1}, b_{1}, c_{1}\right)$, and $\widetilde{T}_{2}=\left(a_{2}, b_{2}, c_{2}\right)$, be two different triangular fuzzy numbers. Addition, subtraction, multiplication, and division operations on fuzzy numbers can be represented as follows:

$$
\begin{gathered}
\widetilde{T}_{1} \oplus \widetilde{T}_{2}=\left(a_{1}+a_{2}, b_{1}+b_{2}, c_{1}+c_{2}\right) \\
\widetilde{T}_{1} \Theta \widetilde{T}_{2}=\left(a_{1}-c_{2}, b_{1}-b_{2}, c_{1}-a_{2}\right) \\
k \otimes \widetilde{T}_{1}=\left\{\begin{array}{c}
\left(k a_{1}, k b_{1}, k c_{1}\right), k>0 \\
\left(k c_{1}, k b_{1}, k a_{1}\right), k<0
\end{array}, \text { where } k\right. \text { is a scalar } \\
\widetilde{T}_{1} \otimes \widetilde{T}_{2} \cong\left(a_{1} * a_{2}, b_{1} * b_{2}, c_{1} * c_{2}\right), \text { if } \mathrm{a}_{1} \geq 0, a_{2} \geq 0 \\
\widetilde{T}_{1} \phi \widetilde{T}_{2} \cong\left(\frac{a_{1}}{c_{2}}, \frac{b_{1}}{b_{2}}, \frac{c_{1}}{a_{2}}\right) \text { if } a_{1} \geq 0, a_{2}>0 .
\end{gathered}
$$

Triangular fuzzy numbers are suitable for measuring uncertain data in decision problems. The main purpose for utilizing triangular fuzzy numbers is expressed as their intuitive and computational-efficient presentation [21].

It is possible to represent a linguistic variable as a variable that has values as words or sentences rather than numbers. Linguistic variables are useful tools for determining the phenomena that cannot be defined via quantitative terms [22].

\subsection{2-Tuple Fuzzy Linguistic Representation Model}

The 2-tuple linguistic representation model was developed by Herrera and Martínez [23] with the aim of advancing a different computational model of fuzzy linguistic approach. Linguistic data is symbolized by a pair of values $\left(s_{i}, \alpha\right)$ where $s_{i}$ is a semantic term from a previously defined linguistic term set $S_{T}$, and $\alpha$ is a number that presents the symbolic translation. The 2-tuple fuzzy representation model yields transformation among linguistic 2-tuples and numbers by describing a set of functions.

When compared with classical models, 2-tuple fuzzy representation has some important advantages. First, 2-tuple fuzzy linguistic representation enables converting information among distinct linguistic term sets without any loss. Moreover, in classical models, the linguistic domain is acted as discrete, while it is able to be acted as continuous in 2-tuple fuzzy linguistic representation [23]. These positive influences enable the utilization of linguistic representation model rational.

Description 1 [23]. Let $L=\left(\gamma_{0}, \gamma_{1}, \ldots, \gamma_{g}\right)$ be accepted as a fuzzy set delineated in $S_{T}$. A conversion function $\chi$ that provides to transform $L$ into a number in the interval of granularity of $S_{T},[0, g]$ can be described as:

$$
\begin{aligned}
& \chi: F\left(S_{T}\right) \rightarrow[0, g], \\
& \chi\left(F\left(S_{T}\right)\right)=\chi\left(\left\{\left(s_{j}, \gamma_{j}\right), j=0,1, \ldots, g\right\}\right)=\frac{\sum_{j=0}^{g} j \gamma_{j}}{\sum_{j=0}^{g} \gamma_{j}}=\beta .
\end{aligned}
$$

where $F\left(S_{T}\right)$ explains the set of fuzzy sets described in $S_{T}$. 
Description 2 [23]. Let $S=\left\{s_{0}, s_{1}, \ldots, s_{g}\right\}$ be accepted as a linguistic term se,t and $\beta \in[0, g]$ be accepted as a value that enables supporting the result of a symbolic unification operation; then, the 2-tuple that expresses the same data to $\beta$ is achieved with the formulation below:

$$
\begin{aligned}
& \Delta:[0, g] \rightarrow S \times[-0.5,0.5), \\
& \Delta(\beta)= \begin{cases}s_{i}, & i=\operatorname{round}(\beta) \\
\alpha=\beta-i, & \alpha \in[-0.5,0.5),\end{cases}
\end{aligned}
$$

where 'round' is classical round operation, $s_{i}$ means the nearest index label to ' $\beta$ ', and ' $\alpha$ ' means the result of the symbolic translation.

Proposition 1 [23]. Let $S=\left\{s_{0}, s_{1}, \ldots, s_{g}\right\}$ be accepted as a linguistic term set, and $\left(s_{i}, \alpha\right)$ be a 2-tuple. There exists a $\Delta^{-1}$ function that gives the identical value $\beta \in[0, g] \subset \Re$ from a 2-tuple. This function is described as:

$$
\begin{aligned}
& \Delta^{-1}: S \times[-0.5,0.5) \rightarrow[0, g] \\
& \Delta^{-1}\left(s_{i}, \alpha\right)=i+\alpha=\beta .
\end{aligned}
$$

Description 3 [24]. Define $x=\left\{\left(s_{1}, \alpha_{1}\right), \ldots,\left(s_{n}, \alpha_{n}\right)\right\}$ as a set of 2-tuples, and $W=\left\{w_{1}, \ldots, w_{n}\right\}$ as their identified importance. The 2-tuple weighted average $\bar{x}^{w}$ can be calculated as:

$$
\bar{x}^{\mathfrak{w}}\left[\left(s_{1}, \alpha_{1}\right), \ldots,\left(s_{n}, \alpha_{n}\right)\right]=\Delta\left(\frac{\sum_{i=1}^{n} \Delta^{-1}\left(s_{i}, \alpha_{i}\right) \cdot w_{i}}{\sum_{i=1}^{n} w_{i}}\right)=\Delta\left(\frac{\sum_{i=1}^{n} \beta_{i} \cdot w_{i}}{\sum_{i=1}^{n} w_{i}}\right)
$$

Description $4[24,25]$. Accept that $x=\left\{\left(s_{1}, \alpha_{1}\right), \ldots,\left(s_{n}, \alpha_{n}\right)\right\}$ is a set of 2-tuples, and $W=$ $\left\{\left(w_{1}, \alpha_{1}^{w}\right), \ldots,\left(w_{n}, \alpha_{n}^{w}\right)\right\}$ is their weights. The 2-tuple linguistic weighted average $\bar{x}_{l}^{w}$ is computed with the function below:

$$
\bar{x}_{l}^{w}\left(\left[\left(s_{1}, \alpha_{1}\right),\left(w_{1}, \alpha_{1}^{w}\right)\right] \ldots\left[\left(s_{n}, \alpha_{n}\right),\left(w_{n}, \alpha_{n}^{w}\right)\right]\right)=\Delta\left(\frac{\sum_{i=1}^{n} \beta_{i} \cdot \beta_{w_{i}}}{\sum_{i=1}^{n} \beta_{w_{i}}}\right)
$$

with $\beta_{i}=\Delta^{-1}\left(s_{i}, \alpha_{i}\right)$ and $\beta_{w i}=\Delta^{-1}\left(w_{i}, \alpha_{i}^{w}\right)$.

\subsection{Linguistic Hierarchies}

The linguistic hierarchy $(\mathrm{LH})$ can be defined as a set of levels in which each level shows a linguistic term set with a different scale from the remaining levels of the hierarchy [26]. A level in this hierarchy can be symbolized as $l(t, n(t))$, where $t$ represents the level of hierarchy, and $n(t)$ represents the granularity of the term set of the level $t$. It is considered that linguistic terms' membership functions are triangular-shaped, symmetrical, and uniformly distributed in [0,1].

The ordering of the levels in a linguistic hierarchy is implemented by taking into account their granularity. For instance, consider two successive levels: $t$ and $t+1, n(t+1)>n(t)$. With this way, the clarification of the previous level is provided.

A linguistic hierarchy, LH, is described as the aggregation of all levels $t$ as $L H=\cup_{t} l(t, n(t))$. It is expressed that the linguistic term set of a level is reached from its predecessor. The linguistic term set of level $t+1$ is constructed from its predecessor as [26]:

$$
L(t, n(t)) \rightarrow L(t+1,2 . n(t)-1)
$$


Table 1 gives the samples of the linguistic hierarchies.

Table 1. Linguistic hierarchies [27].

\begin{tabular}{ccccc}
\hline LH & Level 1 & Level 2 & Level 3 & Level 4 \\
\hline$l(t, n(t))$ & $l(1,3)$ & $l(2,5)$ & $l(3,9)$ & $l(4,17)$ \\
$l(t, n(t))$ & $l(1,7)$ & $l(2,13)$ & & \\
\hline
\end{tabular}

Linguistic hierarchies are utilized to prevent the information loss that appears in the aggregation step of multi-granular data. The conversion function among linguistic terms of the hierarchy can be described as:

$$
\begin{aligned}
& T F_{t^{\prime}}^{t}: l(t, n(t)) \rightarrow l\left(t^{\prime}, n\left(t^{\prime}\right)\right) \\
& T F_{t^{\prime}}^{t}\left(s_{i}^{n(t)}, \alpha^{n(t)}\right)=\Delta\left(\frac{\Delta^{-1}\left(s_{i}^{n(t)}, \alpha^{n(t)}\right)\left(n\left(t^{\prime}\right)-1\right)}{n(t)-1}\right)
\end{aligned}
$$

The bijectivity of transformation function assures the performance of the transformations without information loss [28].

\subsection{Fuzzy COPRAS (Complex Proportional Assessment) Method}

The COPRAS (Complex Proportional Assessment) method was introduced by Zavadskas and Kaklauskas [29]. It is a well-known MADM approach that defines a solution relative to the ideal solution. In the COPRAS method, the most suitable alternative is identified by comparing the direct and proportional ratio of the ideal solution to the ratio of the anti-ideal solution.

It is a well-known fact that in order to express the necessities, preferences, and thoughts, it is not sufficient to use only crisp numbers. Fuzzy set theory was evolved to eliminate this limitation by modeling the uncertainty of human judgments [20]. In classical COPRAS, the ratings of criteria are deterministic values, but in fuzzy COPRAS, the assessments for criteria are described as linguistic terms.

The steps of the fuzzy COPRAS method are shown below [30]:

Step 1: Determine the alternatives and the selection criteria.

The criteria are determined by carrying out a literature survey and utilizing expert knowledge. There are $m$ alternatives denoted as $A_{i}=\left\{A_{1}, A_{2}, \ldots, A_{m}\right\}$, which are evaluated under $n$ criteria, $C_{j}=\left\{C_{1}, C_{2}, \ldots, C_{n}\right\}$.

Step 2: Compose the fuzzy decision matrix $(\widetilde{D})$ that denotes the evaluation of alternatives regarding criteria and the weight matrix of criteria $(\widetilde{W})$ as:

$$
\begin{gathered}
\widetilde{D}=\left[\begin{array}{cccc}
\widetilde{x}_{11} & \widetilde{x}_{12} & \cdots & \widetilde{x}_{1 n} \\
\widetilde{x}_{21} & \widetilde{x}_{22} & \cdots & \widetilde{x}_{2 n} \\
\vdots & \vdots & \ldots & \vdots \\
\widetilde{x}_{m 1} & \widetilde{x}_{m 2} & \cdots & \widetilde{x}_{m n}
\end{array}\right] i=1,2, \ldots, m ; j=1,2, \ldots, n . \\
\widetilde{W}_{j}=\left(\widetilde{w}_{1}, \widetilde{w}_{2} \ldots, \widetilde{w}_{n}\right) j=1,2, \ldots, n .
\end{gathered}
$$

where $\widetilde{x}_{i j}$ and $\widetilde{w}_{j}$ can be represented as $\widetilde{x}_{i j}=\left(x_{i j}^{1}, x_{i j}^{2}, x_{i j}^{3}\right)$ and $\widetilde{w}_{j}=\left(w_{j}^{1}, w_{j}^{2}, w_{j}^{3}\right)$, respectively, in triangular fuzzy number format.

Step 3: Normalize the decision matrix.

Step 4: Compute the weighted normalized decision matrix, $V=\left[\widetilde{v}_{i j}\right]_{m x n^{\prime}}$ as:

$$
\widetilde{v}_{i j}=\widetilde{r}_{i j} w_{j}
$$

where $r_{i j}$ and $w_{j}$ represent the normalized rating of the $i$ th alternative regarding the $j$ th criterion and weight of the $j$ th criterion, respectively. 
Step 5: Compute the sum of the criteria value for benefit-related attributes, for which the greater the performance value, the more its preference, as in Equation (16):

$$
\widetilde{P}_{i}=\sum_{j} \widetilde{v}_{i j}, \quad j \in B_{j}
$$

where $B_{j}$ represents the set of benefit-related criteria.

Step 6: Compute the sum of the criteria value for the cost-related attributes for which the greater the performance value, the less its preference, as in Equation (17):

$$
\widetilde{R}_{i}=\sum_{j} \widetilde{v}_{i j}, \quad j \in C_{j}
$$

where $C_{j}$ represents the set of cost-related criteria.

Step 7: Compute the relative weight of alternatives as:

$$
\widetilde{Q}_{i}=\widetilde{P}_{i}+\frac{\widetilde{R}_{\min } \sum_{i} \widetilde{R}_{i}}{\widetilde{R}_{i} \sum_{i} \frac{\widetilde{R}_{\min }}{\widetilde{R}_{i}}}
$$

Step 8: $\widetilde{Q}_{i}=\left(q_{i}^{1}, q_{i}^{2}, q_{i}^{3}\right)$ is transformed to non-fuzzy via Equation (19):

$$
Q_{i}=\frac{\left(q_{i}^{3}-q_{i}^{1}\right)+\left(q_{i}^{2}-q_{i}^{1}\right)}{3}+q_{i}^{1}
$$

Step 9: Determine the priority of the alternatives $\left(N_{i}\right)$ using Equation (20) and rank the alternatives:

$$
N_{i}=\frac{Q_{i}}{Q_{\max }} 100 \%
$$

\subsection{Developed Fuzzy Decision-Making Methodology}

This part presents the fuzzy group decision-making method, which employed QFD, linguistic hierarchies, the 2-tuple fuzzy linguistic representation model, and fuzzy COPRAS. The detailed stepwise representation of the proposed methodology is explained below.

Step 1. Compose a decision makers' commission of $Z(z=1,2, \ldots, Z)$ decision makers, and determine the CRs $(i=1,2, \ldots, m)$ and evaluation criteria $(j=1,2, \ldots, n)$.

Step 2. Formulate the decision matrices for experts that denote the weights of each CRs, $\widetilde{w}_{i z}$, the relationships between CRs and TAs, $\widetilde{x}_{i j z}$, the interrelationships between TAs and $\widetilde{y}_{k j z}$, and the assessments of alternatives concerning each TA.

Step 3. Unify the multigranular linguistic data provided by the experts into a linguistic term set using Equation (12).

Step 4. Aggregate the weights of each CR, the relationships among the CRs and TAs, and the interrelationships between the TAs employing the arithmetic mean operator.

Step 5. Calculate the $\beta$ values of the aggregated ratings by using Equation (6).

Step 6. Calculate the original relationship among the $j$ th TA and the $i$ th $\mathrm{CR}, \widetilde{x}_{i j}^{*}$, employing Equation (10).

Step 7. Compute the 2-tuple linguistic weighted average for TAs by using Equation (9).

Step 8. Aggregate the fuzzy ratings of alternatives by using the arithmetic mean operator.

Step 9. Employ the fuzzy COPRAS method for ranking alternatives by considering the computed 2-tuple linguistic weighted average at step 7 as the weights of evaluation criteria. 


\subsection{Structure of the Problem and Experts Survey}

The illustration of the developed method is represented by a case study conducted in a detergent manufacturer factory located in the south part of Turkey [31]. The factory was founded in 2005 in Adana, which is the south part of Turkey. Peros, Asperox, Sev, and Halk branded products are produced and brought to the customer. It contributes positively to Turkey's economy by marketing its products to the Middle East, Africa, the Balkans, and Turkic Republics. The factory has a capacity of producing 1500 tons detergent in a day, and it is ranked among the top five detergent manufacturers in Turkey.

First, an analysis is conducted with the research and development (R\&D) department, and then, the features of the washing liquids, the expectations of customers, and the factors that affect the production process are stated. Finally, a survey is constructed with the contribution of the R\&D department. Five CRs through the expectations of customers are decided. These can be listed as "easy resolution in water $\left(\mathrm{CR}_{1}\right)$ ", "eco-friendly $\left(\mathrm{CR}_{2}\right)^{\prime}$, " anti-allergen $\left(\mathrm{CR}_{3}\right)$ ", "cost-effective $\left(\mathrm{CR}_{4}\right)^{\prime}$, and "hygienic $\left(\mathrm{CR}_{5}\right)$ ". Five TAs that are considered as evaluation criteria can be listed as " $\mathrm{pH}\left(\mathrm{TA}_{1}\right)$ ", "viscosity $\left(\mathrm{TA}_{2}\right)$ ", "anionic active material $\left(\mathrm{TA}_{3}\right)$ ", "nonionic active material $\left(\mathrm{TA}_{4}\right)$ ", "total active material $\left(\mathrm{TA}_{5}\right)^{\prime \prime}$.

Four experts $\left(D M_{1}, D M_{2}, D M_{3}, D M_{4}\right)$ stated their opinions on the prepared survey. The linguistic hierarchy, $L H=\bigcup_{t} l(1,3)$, which is given in Figure 2, is assumed as a multi-granular linguistic context, because the scale of its linguistic term sets is prevalent in decision-making problems.

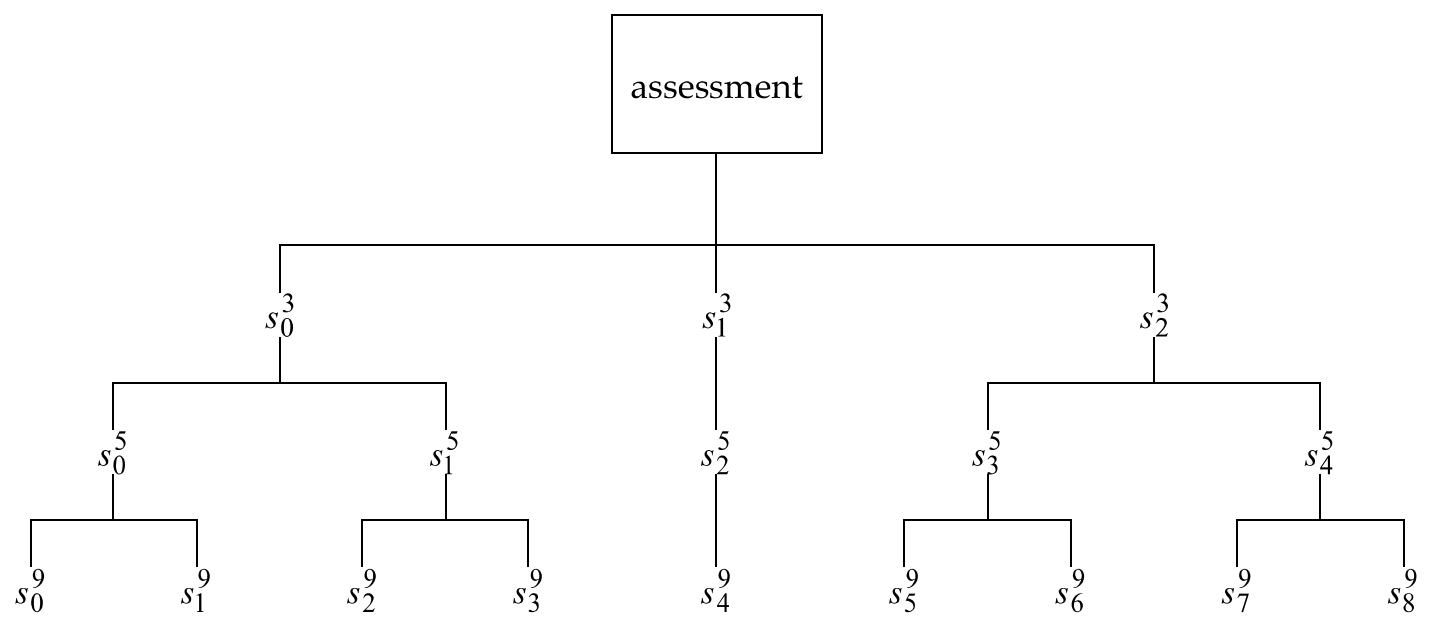

Figure 2. Multi-granular linguistic context.

$D M_{1}$ used $l(1,3), D M_{2}$ and $D M_{3}$ utilized $l(2,5), D M_{4}$ chose to use $l(3,9)$, and $D M_{3}$ wanted to use $l(3,9)$ for rating the prepared survey. First, the decision makers provided their opinions on the effects of each TA on each CR. Then, they stated the weights of each CR, and finally, the dependencies among the TAs were given. The linguistic term set $l(2,5)$ is preferred as the linguistic terms set to unify the multi-granular data given by the experts. The ratings of four experts are presented in Tables 2-4. 
Table 2. The ratings of decision makers (DMs) regarding the relationship between (customer requirements (CRs) and technical attributes (TAs).

\begin{tabular}{cccccc}
\hline $\mathbf{C R s}$ & $\mathbf{T A}_{\mathbf{1}}$ & $\mathbf{T A}_{\mathbf{2}}$ & $\mathbf{T A}_{\mathbf{3}}$ & $\mathbf{T A}_{4}$ & $\mathbf{T A}_{5}$ \\
\hline $\mathrm{CR}_{1}$ & $s_{0}^{3}, s_{1}^{5}, s_{1}^{5}, s_{2}^{9}$ & $s_{0}^{3}, s_{1}^{5}, s_{2}^{5}, s_{2}^{9}$ & $s_{1}^{3}, s_{3}^{5}, s_{3}^{5}, s_{6}^{9}$ & $s_{2}^{3}, s_{4}^{5}, s_{4}^{5}, s_{7}^{9}$ & $s_{2}^{3}, s_{3}^{5}, s_{4}^{5}, s_{7}^{9}$ \\
$\mathrm{CR}_{2}$ & $s_{1}^{3}, s_{3}^{5}, s_{2}^{5}, s_{5}^{9}$ & $s_{0}^{3}, s_{1}^{5}, s_{1}^{5}, s_{2}^{9}$ & $s_{2}^{3}, s_{3}^{5}, s_{4}^{5}, s_{7}^{9}$ & $s_{2}^{3}, s_{3}^{5}, s_{4}^{5}, s_{6}^{9}$ & $s_{1}^{3}, s_{4}^{5}, s_{3}^{5}, s_{7}^{9}$ \\
$\mathrm{CR}_{3}$ & $s_{0}^{3}, s_{1}^{5}, s_{1}^{5}, s_{3}^{9}$ & $s_{1}^{3}, s_{2}^{5}, s_{2}^{5}, s_{3}^{9}$ & $s_{2}^{3}, s_{4}^{5}, s_{3}^{5}, s_{7}^{9}$ & $s_{1}^{3}, s_{3}^{5}, s_{3}^{5}, s_{6}^{9}$ & $s_{1}^{3}, s_{3}^{5}, s_{4}^{5}, s_{6}^{9}$ \\
$\mathrm{CR}_{4}$ & $s_{0}^{3}, s_{1}^{5}, s_{0}^{5}, s_{2}^{9}$ & $s_{2}^{3}, s_{3}^{5}, s_{2}^{5}, s_{5}^{9}$ & $s_{2}^{3}, s_{3}^{5}, s_{4}^{5}, s_{8}^{9}$ & $s_{2}^{3}, s_{3}^{5}, s_{4}^{5}, s_{7}^{9}$ & $s_{2}^{3}, s_{3}^{5}, s_{4}^{5}, s_{6}^{9}$ \\
$\mathrm{CR}_{5}$ & $s_{2}^{3}, s_{3}^{5}, s_{3}^{5}, s_{7}^{9}$ & $s_{1}^{3}, s_{2}^{5}, s_{3}^{5}, s_{4}^{9}$ & $s_{2}^{3}, s_{3}^{5}, s_{3}^{5}, s_{6}^{9}$ & $s_{2}^{3}, s_{3}^{5}, s_{3}^{5}, s_{6}^{9}$ & $s_{1}^{3}, s_{3}^{5}, s_{4}^{5}, s_{5}^{9}$ \\
\hline
\end{tabular}

Table 3. The ratings of DMs regarding the importance of CRs.

\begin{tabular}{cc}
\hline CRs & Importance of CRs \\
\hline $\mathrm{CR}_{1}$ & $s_{1}^{3}, s_{3}^{5}, s_{2}^{5}, s_{6}^{9}$ \\
$\mathrm{CR}_{2}$ & $s_{2}^{3}, s_{4}^{5}, s_{3}^{5}, s_{7}^{9}$ \\
$\mathrm{CR}_{3}$ & $s_{2}^{3}, s_{3}^{5}, s_{4}^{5}, s_{6}^{9}$ \\
$\mathrm{CR}_{4}$ & $s_{1}^{3}, s_{3}^{5}, s_{2}^{5}, s_{6}^{9}$ \\
$\mathrm{CR}_{5}$ & $s_{2}^{3}, s_{4}^{5}, s_{3}^{5}, s_{7}^{9}$ \\
\hline
\end{tabular}

Table 4. The ratings of DMs regarding the relationship among the TAs.

\begin{tabular}{cccccc}
\hline TAs & $\mathbf{T A}_{\mathbf{1}}$ & $\mathbf{T A}_{\mathbf{2}}$ & $\mathbf{T A}_{\mathbf{3}}$ & $\mathbf{T A}_{\mathbf{4}}$ & $\mathbf{T A}_{\mathbf{5}}$ \\
\hline $\mathrm{TA}_{1}$ & - & $s_{2}^{3}, s_{3}^{5}, s_{2}^{5}, s_{6}^{9}$ & $s_{0}^{3}, s_{1}^{5}, s_{2}^{5}, s_{3}^{9}$ & $s_{0}^{3}, s_{1}^{5}, s_{1}^{5}, s_{3}^{9}$ & $s_{1}^{3}, s_{2}^{5}, s_{2}^{5}, s_{4}^{9}$ \\
$\mathrm{TA}_{2}$ & $s_{2}^{3}, s_{3}^{5}, s_{2}^{5}, s_{6}^{9}$ & - & $s_{2}^{3}, s_{3}^{5}, s_{4}^{5}, s_{7}^{9}$ & $s_{1}^{3}, s_{4}^{5}, s_{3}^{5}, s_{6}^{9}$ & $s_{2}^{3}, s_{4}^{5}, s_{4}^{5}, s_{8}^{9}$ \\
$\mathrm{TA}_{3}$ & $s_{0}^{3}, s_{1}^{5}, s_{2}^{5}, s_{3}^{9}$ & $s_{2}^{3}, s_{3}^{5}, s_{4}^{5}, s_{7}^{9}$ & - & $s_{1}^{3}, s_{2}^{5}, s_{3}^{5}, s_{6}^{9}$ & $s_{2}^{3}, s_{4}^{5}, s_{3}^{5}, s_{6}^{9}$ \\
$\mathrm{TA}_{4}$ & $s_{0}^{3}, s_{1}^{5}, s_{1}^{5}, s_{3}^{9}$ & $s_{1}^{3}, s_{4}^{5}, s_{3}^{5}, s_{6}^{9}$ & $s_{1}^{3}, s_{2}^{5}, s_{3}^{5}, s_{6}^{9}$ & - & $s_{2}^{3}, s_{3}^{5}, s_{3}^{5}, s_{7}^{9}$ \\
$\mathrm{TA}_{5}$ & $s_{1}^{3}, s_{2}^{5}, s_{2}^{5}, s_{4}^{9}$ & $s_{2}^{3}, s_{4}^{5}, s_{4}^{5}, s_{8}^{9}$ & $s_{2}^{3}, s_{4}^{5}, s_{3}^{5}, s_{6}^{9}$ & $s_{2}^{3}, s_{3}^{5}, s_{3}^{5}, s_{7}^{9}$ & - \\
\hline
\end{tabular}

Then, a committee of three experts evaluated the ingredients of six washing liquid formulations, according to TAs.

The experts utilized the linguistic term set provided in Table 5 for the evaluation, which is given in Table 6.

Table 5. Fuzzy terms and their numerical values.

\begin{tabular}{cc}
\hline Linguistic Terms & Fuzzy Numerical Values \\
\hline VL (Very Low) & $(0,0,0.25)$ \\
L (Low) & $(0,0.25,0.50)$ \\
M (Medium) & $(0.25,0.50,0.75)$ \\
H (High) & $(0.50,0.75,1)$ \\
VH (Very High) & $(0.75,1,1)$ \\
\hline
\end{tabular}

Table 6. Linguistic ratings of DMs for formulations.

\begin{tabular}{cccccc}
\hline Formulations & TA $_{\mathbf{1}}$ & TA $_{\mathbf{2}}$ & TA $_{\mathbf{3}}$ & TA $_{\mathbf{4}}$ & TA $_{\mathbf{5}}$ \\
\hline Formulation1 & $(\mathrm{H}, \mathrm{M}, \mathrm{H})$ & $(\mathrm{H}, \mathrm{H}, \mathrm{M})$ & $(\mathrm{VH}, \mathrm{H}, \mathrm{M})$ & $(\mathrm{VH}, \mathrm{H}, \mathrm{M})$ & $(\mathrm{VH}, \mathrm{H}, \mathrm{M})$ \\
Formulation2 & $(\mathrm{H}, \mathrm{M}, \mathrm{M})$ & $(\mathrm{M}, \mathrm{M}, \mathrm{L})$ & $(\mathrm{M}, \mathrm{M}, \mathrm{M})$ & $(\mathrm{H}, \mathrm{M}, \mathrm{L})$ & $(\mathrm{M}, \mathrm{M}, \mathrm{L})$ \\
Formulation3 & $(\mathrm{M}, \mathrm{L}, \mathrm{M})$ & $(\mathrm{M}, \mathrm{M}, \mathrm{H})$ & $(\mathrm{H}, \mathrm{H}, \mathrm{M})$ & $(\mathrm{H}, \mathrm{M}, \mathrm{M})$ & $(\mathrm{M}, \mathrm{H}, \mathrm{M})$ \\
Formulation4 & $(\mathrm{H}, \mathrm{M}, \mathrm{H})$ & $(\mathrm{H}, \mathrm{VH}, \mathrm{H})$ & $(\mathrm{H}, \mathrm{M}, \mathrm{H})$ & $(\mathrm{M}, \mathrm{H}, \mathrm{H})$ & $(\mathrm{H}, \mathrm{M}, \mathrm{M})$ \\
Formulation5 & $(\mathrm{M}, \mathrm{M}, \mathrm{M})$ & $(\mathrm{VH}, \mathrm{H}, \mathrm{M})$ & $(\mathrm{H}, \mathrm{L}, \mathrm{M})$ & $(\mathrm{H}, \mathrm{H}, \mathrm{M})$ & $(\mathrm{M}, \mathrm{L}, \mathrm{L})$ \\
Formulation6 & $(\mathrm{H}, \mathrm{M}, \mathrm{H})$ & $(\mathrm{M}, \mathrm{H}, \mathrm{H})$ & $(\mathrm{M}, \mathrm{M}, \mathrm{H})$ & $(\mathrm{L}, \mathrm{M}, \mathrm{M})$ & $(\mathrm{M}, \mathrm{H}, \mathrm{M})$ \\
\hline
\end{tabular}




\section{Results}

By using the data derived from the interviews with the decision makers, firstly, the most important evaluation criteria for the washing liquid material selection procedure is determined; then, the most appropriate washing liquid formulation is identified. The necessary calculations of the developed methodology referring to the abovementioned problem are given below.

The unified ratings of experts are merged using an arithmetic mean operator, as shown in Figure 3.

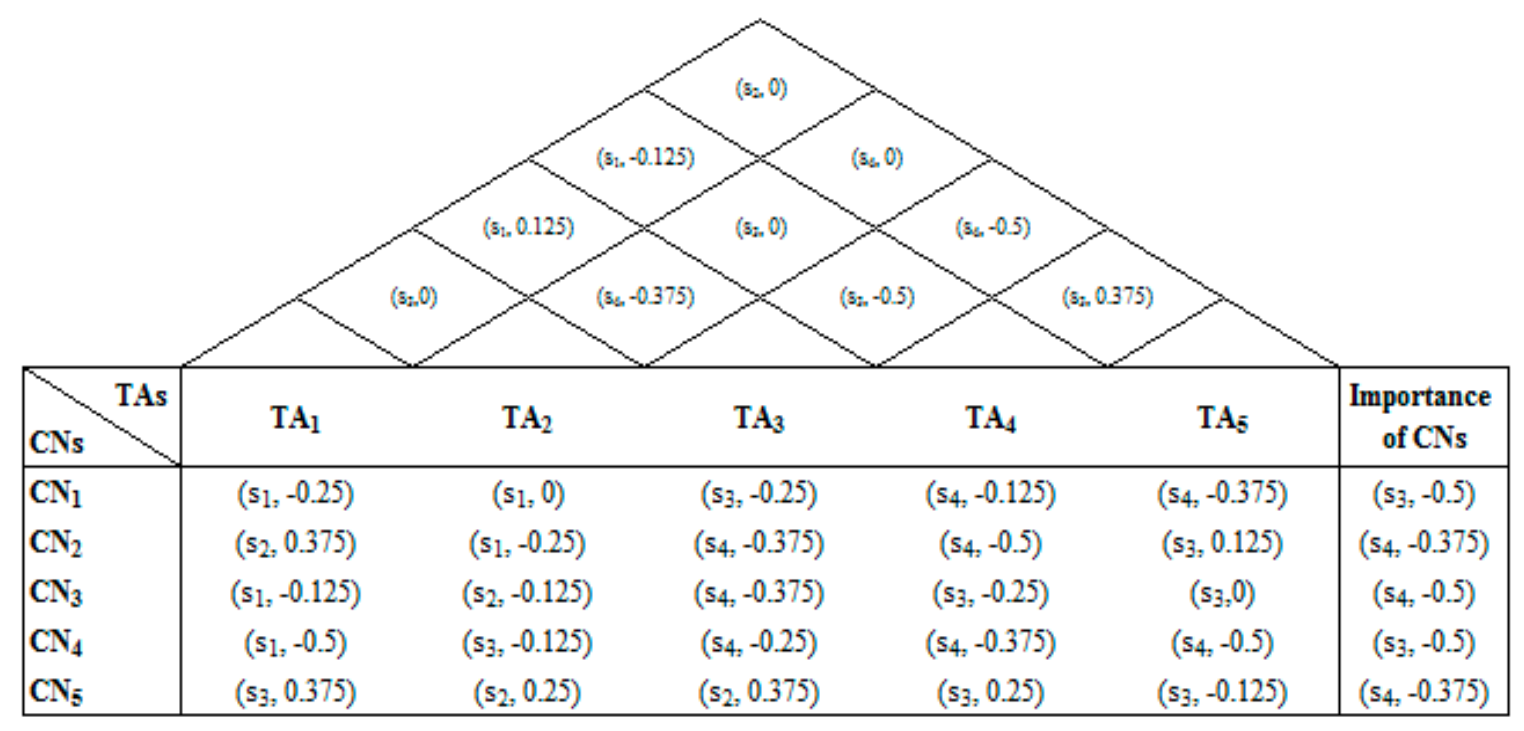

Figure 3. Unified assessments of decision makers.

The original relationship measure between CRs and TAs is calculated as in Table 7.

Table 7. Original relationship between CRs and TAs.

\begin{tabular}{cccccc}
\hline $\mathbf{C R s}$ & $\mathbf{T A}_{\mathbf{1}}$ & $\mathbf{T A}_{\mathbf{2}}$ & $\mathbf{T A}_{\mathbf{3}}$ & $\mathbf{T A}_{\mathbf{4}}$ & $\mathbf{T A}_{\mathbf{5}}$ \\
\hline $\mathrm{CR}_{1}$ & $\left(s_{2},-0.21\right)$ & $\left(s_{2}, 0.40\right)$ & $\left(s_{3},-0.43\right)$ & $\left(s_{3},-0.22\right)$ & $\left(s_{3},-0.47\right)$ \\
$\mathrm{CR}_{2}$ & $\left(s_{2}, 0.29\right)$ & $\left(s_{3},-0.37\right)$ & $\left(s_{3},-0.32\right)$ & $\left(s_{3},-0.24\right)$ & $\left(s_{3},-0.35\right)$ \\
$\mathrm{CR}_{3}$ & $\left(s_{2},-0.04\right)$ & $\left(s_{2}, 0.47\right)$ & $\left(s_{3},-0.31\right)$ & $\left(s_{3},-0.34\right)$ & $\left(s_{3},-0.44\right)$ \\
$\mathrm{CR}_{4}$ & $\left(s_{2}, 0.27\right)$ & $\left(s_{3},-0.08\right)$ & $\left(s_{3}, 0.21\right)$ & $\left(s_{3}, 0.26\right)$ & $\left(s_{3}, 0.07\right)$ \\
$\mathrm{CR}_{5}$ & $\left(s_{3},-0.13\right)$ & $\left(s_{3},-0.22\right)$ & $\left(s_{3},-0.31\right)$ & $\left(s_{3},-0.21\right)$ & $\left(s_{3},-0.24\right)$ \\
\hline
\end{tabular}

Then, the 2-tuple linguistic weighted averages for TAs and the importance of TAs are counted, as shown in Table 8.

Table 8. Importance of TAs.

\begin{tabular}{cccccc}
\hline & $\mathbf{T A}_{\mathbf{1}}$ & $\mathbf{T A}_{\mathbf{2}}$ & $\mathbf{T A}_{\mathbf{3}}$ & $\mathbf{T A}_{\mathbf{4}}$ & $\mathbf{T A}_{\mathbf{5}}$ \\
\hline Importance & $\left(s_{2}, 0.27\right)$ & $\left(s_{3},-0.36\right)$ & $\left(s_{3},-0.25\right)$ & $\left(s_{2}, 0.24\right)$ & $\left(s_{3},-0.30\right)$ \\
\hline
\end{tabular}

Formulations are ranked by employing the fuzzy COPRAS method. The solutions are given in Table 9. 
Table 9. Ranking of the alternatives.

\begin{tabular}{cccc}
\hline Formulation & $\tilde{Q}_{\boldsymbol{i}}$ & $\boldsymbol{N}_{\boldsymbol{i}}$ & Rank \\
\hline 1 & $(0.50,0.77,0.98)$ & 100 & 1 \\
2 & $(0.25,0.52,0.78)$ & 68.57 & 6 \\
3 & $(0.34,0.61,0.88)$ & 81.48 & 4 \\
4 & $(0.46,0.73,0.98)$ & 96.36 & 2 \\
5 & $(0.31,0.58,0.83)$ & 76.62 & 5 \\
6 & $(0.36,0.63,0.89)$ & 83.40 & 3 \\
\hline
\end{tabular}

\section{Discussion}

In previous studies, different fuzzy MCDM methods have been developed for material selection. Although these methods enable handling fuzzy data, they have some disadvantages. Defuzzification is generally applied in fuzzy MCDM approaches. Freeling [32] stated that reducing all analyses to a single number will result in information loss. Therefore, defuzzification contradicts the purpose of reducing information loss. Besides, AHP and ANP techniques are used for pairwise comparison. This comparison gets harder when the number of alternatives or criteria increases. In the material selection process, the company's primary objective is to identify materials that satisfy a predefined quality standard regarding the customer expectations. Thus, implementing a house of quality is important to determine how well each material attribute covers the product specifications. Although previous studies that are found in the literature proposed methodologies for material selection, other studies should be conducted to consider vague information about the priority of the consumer requirements, the relationship between the consumer requirements and the features of materials, and dependencies among the material evaluation criteria in the analysis. Furthermore, the degree of uncertainty may differ depending on the decision makers' different experiences in group decision-making approaches. Therefore, the scale of the linguistic variables that they use may be different. Thus, it is necessary to employ a heterogeneous linguistic scale in modeling real-world problems. In this paper, a fuzzy MCGDM methodology that integrates QFD, 2-tuple fuzzy linguistic representation, and linguistic hierarchies is presented. The importance of the evaluation criteria is obtained benefiting from HOQ, which enables incorporating customer expectations into the evaluation process, as well as dealing with the impacts of the relationships between the customer expectations and material evaluation criteria, and the relationships between the material selection attributes, for reaching higher satisfaction in order to meet company's needs. Besides, the developed framework enables experts to utilize different linguistic scales by unifying the heterogeneous linguistic data and employing 2-tuple fuzzy linguistic representation and linguistic hierarchies without incurring information when making computations using linguistic variables. Hence, the proposed approach enables dealing with the information loss problem that appears when employing conventional fuzzy MCDM models.

The managerial implications of the study can be listed as follows. This study specifies the importance of various washing liquid material selection attributes regarding customer expectations. In this way, in the new product design, the most appropriate product will be created, and customer loyalty will be provided. The company's competitiveness and market dominance will increase. An analysis is conducted to determine what the customers wants from a washing liquid. For this purpose, surveys and interviews were conducted with customers in the region. According to the results of the survey, customer expectations were determined, and the five most common customer expectations were taken into consideration in the study. These can be listed as "easy resolution in water" $\left(\mathrm{CR}_{1}\right)$, "eco-friendly" $\left(\mathrm{CR}_{2}\right)$, "anti-allergen" $\left(\mathrm{CR}_{3}\right)$, "cost effective" $\left(\mathrm{CR}_{4}\right)$, and "hygienic" $\left(\mathrm{CR}_{5}\right)$. The formulation of washing liquid has different properties. The ratio of these characteristics to meet customer expectations varies. In order to meet customer expectations, the company has to determine product specifications. QFD was used for this purpose; product characteristics and customer expectations were correlated, and the importance levels were determined for product 
properties. The washing liquid formulation, which will be formed by taking these importance levels into consideration, will meet the customer expectations. According to the results of the analysis, "anionic active material" $\left(\mathrm{TA}_{3}\right)$ is determined to be the most important evaluation criteria for the washing liquid material selection procedure, which is followed by "total active material" $\left(\mathrm{TA}_{5}\right)$, "viscosity" $\left(\mathrm{TA}_{2}\right)$, " $\mathrm{pH}$ " $\left(\mathrm{TA}_{1}\right)$, and "nonionic active material" $\left(\mathrm{TA}_{4}\right)$, respectively. Active materials are among the most significant ingredients found in detergents, which present the main implementations of these compounds. Active materials constitute nearly $60 \%$ of the compound of the detergents. They are apt to remove soil (oil, grease, dust, particles...) from solid surfaces. These substances are very useful in industrial terms, but they have significant harmful effects for human life and the ecosystem. Thus, the amount of anionic active material in the formulation is very important. The results of this analysis identify anionic active material and total active material as the most significant criteria, which is compatible with industrial applications. The case company has six different washing liquid formulations, which have their own strengths and weaknesses. The company has not yet conducted any analytical procedure to identify the most appropriate one. This paper also designates the most relevant formulation by considering the importance of the technical attributes that were obtained in the first part of the study. The developed approach can easily be used for the problems in the diverse sectors that can be presented in a HOQ structure. This allows managers to consider customer expectations in the new product development process, which meets the desires of higher quality at a lower cost.

The developed approach acquires some innovative aspects with respect to the existing approaches. The developed method allows dealing with the relationships between the customer needs and material selection attributes, and also the relationships between material selection attributes for assuring higher customer satisfaction. Furthermore, the proposed approach is a group decision-making procedure that allows the decision makers to present the similarities and differences in their opinions; the degree of uncertainty may differ depending on the decision makers' different experiences and knowhow. The existing fuzzy MCDM models only can manage homogenous data; however, in this work, heterogeneous information are available. Thus, the 2-tuple linguistic model and linguistic hierarchies are integrated with QFD for incorporating multi-granular information into the decision framework. Thus, the developed approach enables managers to handle heterogeneous data, and enables decision makers to utilize different linguistic scales. Besides, the problem of information loss that occurs in linguistic computing is overcome via 2-tuple linguistic computing. Hence, the proposed approach enables coping with the information loss problem that we faced when employing conventional fuzzy MCDM models.

As far as we are aware, there is no earlier study in the literature that enables handling heterogeneous data provided by a group of experts, which also takes into account the correlations between customer requirements and product characteristics and the inner dependencies between product characteristics. Thus, it is not possible to compare the obtained results with existing methods. In here, the TOPSIS method, which is also a distance-based MCDM method, is employed instead of COPRAS for comparison purposes. The TOPSIS method determines formulation 4 as the most valuable alternative, which is followed by formulation 1 . Both methods yield the same results in the first two ranks; besides, the case company has been using formulation 4 and 1, considering the customer satisfaction surveys. The findings of the proposed approach are similar to the results from the real-life selection of formulation by the company, which demonstrates the robustness of the framework and promoted its utilization as a decision tool for further material evaluation problems encountered by a company's management.

\section{Conclusions}

In the rapidly changing manufacturing sector, remaining competitive strictly depends on optimizing the business process. While producing a product, always taking correct steps is vital. Making an inappropriate or incorrect decision may lead to big damages that cannot be compensated. 
Decision-making is a familiar problem that is experienced in all stages of life. Material selection can be count as an important decision-making problem. To form a product that shows maximum performance at minimum cost is a sign of a successful material selection process.

In this study, a fuzzy MCGDM algorithm, which integrates 2-tuple linguistic modeling, linguistic hierarchies, and QFD, was proposed to identify the weights of selection attributes in a material selection procedure. After obtaining the importance of selection criteria, by employing the fuzzy COPRAS method, the most appropriate detergent that meets the needs among six alternatives was determined.

Employing the proposed decision making approach to real-world cases in distinct sectors can be the future research direction of this study.

Author Contributions: Conceptualization, M.D. and Ö.A.; Methodology, M.D.; Formal Analysis, M.D. and Ö.A.; Investigation, M.D. and Ö.A.; Data Curation, Ö.A.; Writing-Original Draft Preparation, M.D.; Writing—Review \& Editing, M.D.; Visualization, M.D.; Supervision, M.D.

Funding: This research received no external funding.

Conflicts of Interest: The authors declare no conflict of interest.

\section{References}

1. Mu, J.; Thomas, E.; Peng, G.; Benedetto, A.D. Strategic orientation and new product development performance: The role of networking capability and networking ability. Ind. Mark. Manag. 2017, 64, 187-201. [CrossRef]

2. Relich, M.; Pawlewski, P. A fuzzy weighted average approach for selecting portfolio of new product development projects. Neurocomputing 2017, 231, 19-27. [CrossRef]

3. Hasanzadeh, R.; Azdast, T.; Lee, R.E.; Ghazi, A.A. Experimental polymeric nanocomposite material selection for automotive bumper beam using multi-criteria decision making methods. Iran. J. Mater. Sci. Eng. 2017, 14, 1-10. [CrossRef]

4. Xue, Y.X.; You, J.X.; Lai, X.D.; Liu, H.C. An interval-valued intuitionistic fuzzy MABAC approach for material selection with incomplete weight information. Appl. Soft Comput. 2016, 38, 703-713. [CrossRef]

5. Liu, H.C.; Liu, L.; Wu, J. Material selection using an interval 2-tuple linguistic VIKOR method considering subjective and objective weights. Mater. Des. 2013, 52, 158-167. [CrossRef]

6. Ballestero, E. Selecting textile products by manufacturing companies under uncertainty. Asia-Pac. J. Oper. Res. 2004, 21, 141-161. [CrossRef]

7. Chatterjee, P.; Chakraborty, S. Material selection using preferential ranking methods. Mater. Des. 2012, 35, 384-393. [CrossRef]

8. Girubha, R.J.; Vinodh, S. Application of fuzzy VIKOR and environmental impact analysis for material selection of an automotive component. Mater. Des. 2012, 37, 478-486. [CrossRef]

9. Rahman, S.; Odeyinka, H.; Perera, S.; Bi, Y. Product-cost modelling approach for the development of a decision support system for optimal roofing material selection. Expert Syst. Appl. 2012, 39, 6857-6871. [CrossRef]

10. Anajkumar, L.; Ilangkumaran, M.; Sasirekha, V. Comparative analysis of MCDM methods for pipe material selection in sugar industry. Expert Syst. Appl. 2014, 41, 2964-2980. [CrossRef]

11. Liu, H.C.; You, J.X.; Zhen, L.; Fan, X.J. A novel hybrid multiple criteria decision making model for material selection with target-based criteria. Mater. Des. 2014, 60, 380-390. [CrossRef]

12. Liao, T.W. Two interval type 2 fuzzy TOPSIS material selection methods. Mater. Des. 2015, 88, 1088-1099. [CrossRef]

13. Govindan, K.; Shankar, K.M.; Kannan, D. Sustainable material selection for construction industry-A hybrid multicriteria decision making approach. Renew. Sustain. Energy Rev. 2016, 55, 1274-1288. [CrossRef]

14. Zindani, D.; Maity, S.R.; Bhowmik, S.; Chakraborty, S. A material selection approach using the TODIM (TOmada de Decisao Interativa Multicriterio) method and its analysis. Int. J. Mater. Res. 2017, 108, 345-354. [CrossRef]

15. Zhang, H.; Yong, P.; Tian, G.; Wang, D.; Xie, P. Green material selection for sustainability: A hybrid MCDM approach. PLoS ONE 2017, 12. [CrossRef] [PubMed] 
16. Mousavi-Nasab, S.; Sotoudeh-Anvari, A. A new multi-criteria decision making approach for sustainable material selection problem: A critical study on rank reversal problem. J. Clean. Prod. 2018, 182, 466-484. [CrossRef]

17. Ercan, S.; Bilal, S. The selection of material in dental implant with entropy based simple additive weighting and analytic hierarchy process methods. Sigma J. Eng. Nat. Sci.-Sigma Muhendislik ve Fen Bilimleri Dergisi 2018, 36, 731-740.

18. Carnevalli, J.A.; Miguel, P.C. Review, analysis and classification of the literature on QFD-Types of research, difficulties and benefits. Int. J. Prod. Econ. 2008, 114, 737-754. [CrossRef]

19. Karsak, E.E.; Sozer, S.; Alptekin, S.E. Product planning in quality function deployment using a combined analytic network process and goal programming approach. Comput. Ind. Eng. 2003, 44, 171-190. [CrossRef]

20. Zadeh, L.A. Fuzzy sets. Inf. Control 1965, 8, 338-353. [CrossRef]

21. Karsak, E.E. Distance-based fuzzy MCDM approach for evaluating flexible manufacturing system alternatives. Int. J. Prod. Res. 2002, 40, 3167-3181. [CrossRef]

22. Zadeh, L.A. The concept of a linguistic variable and its application to approximate reasoning-I. Inf. Sci. 1975, 8, 199-249. [CrossRef]

23. Herrera, F.; Martinez, L. A 2-tuple fuzzy linguistic representation model for computing with words. IEEE Trans. Fuzzy Syst. 2000, 8, 746-752. [CrossRef]

24. Herrera-Viedma, E.; Herrera, F.; Martínez, L.; Herrera, J.C.; López, A.G. Incorporating filtering techniques in a fuzzy linguistic multi-agent model for information gathering on the web. Fuzzy Sets Syst. 2004, 148, 61-83. [CrossRef]

25. Wang, W.P. A fuzzy linguistic computing approach to supplier evaluation. Appl. Math. Model. 2010, 34, 3130-3141. [CrossRef]

26. Herrera, F.; Martinez, L. A model based on linguistic 2-tuples for dealing with multigranular hierarchical linguistic contexts in multi-expert decision-making. IEEE Trans. Syst. Man Cybern. B 2001, 31, 227-234. [CrossRef] [PubMed]

27. Herrera, F.; Herrera-Viedma, E.; Martinez, L. A fuzzy linguistic methodology to deal with unbalanced linguistic term sets. IEEE Trans. Fuzzy Syst. 2008, 16, 354-370. [CrossRef]

28. Cordon, O.; Herrera, F.; Zwir, I. Linguistic modeling by hierarchical systems of linguistic rules. IEEE Trans. Fuzzy Syst. 2002, 10, 2-20. [CrossRef]

29. Zavadskas, E.K.; Kaklauskas, A. Determination of an effcient contractor by using the new method of multicriteria assessment. In International Symposium for "The Organisation and Management of Construction". Shaping Theory and Practice. Managing the Construction Project and Managing Risk; Langford, D.A., Retik, A., Eds.; CIB W: London, UK, 1996; Volume 65, pp. 95-104.

30. Zarbakhsnia, N.; Soleimani, H.; Ghaderi, H. Sustainable third-party reverse logistics provider evaluation andselection using fuzzy SWARA and developed fuzzy COPRAS in the presence of risk criteria. Appl. Spft Comput. 2018, 65, 307-319. [CrossRef]

31. Arslan, Ö. Washing Liquid Material Selection Using Fuzzy Multicriteria Decision-Making Approach. Master's Thesis, Galatasaray University, İstanbul, Turkey, 2016.

32. Freeling, S. Fuzzy Sets and Decision Analysis. IEEE Trans. Syst. Man Cybern. 1980, 10, 341-354. [CrossRef]

(C) 2018 by the authors. Licensee MDPI, Basel, Switzerland. This article is an open access article distributed under the terms and conditions of the Creative Commons Attribution (CC BY) license (http://creativecommons.org/licenses/by/4.0/). 